refer to other published work that supports their arguments and ignore papers that do not.

The next few articles will illustrate some ways in which errors at different stages of a study can compromise the ethical status of the research, and discuss some ways in which they may be avoided. These will serve only as examples, since it is impossible to be comprehensive. In the final article I will consider the role of the medical journals in this context.

\section{References}

1 Galton F. Natural inheritance. London: Macmillan, 1889.

${ }^{2}$ Barnett V. The study of outliers: purpose and model. Applied Statistics $1978 ; 27: 242-50$.

3 Chamberlain R. Birth weight and length of gestation. In: British births 1970. Vol 1. The first week of life. National Birthday Trust Fund and Royal College of Obstetricians and Gynaecologists. London: Heinemann, 1975.

- Denham MJ, Foster A, Tyrrell DAJ. Work of a district ethical committee. Br Med $\mathcal{F} 1979$;ii:1042-5.
5 May WW. The composition and function of ethical committees. $\mathcal{f}$ Med Ethics 1975;1:23-9.

6 Sackett DL. Bias in analytic research. $\mathcal{F}$ Chronic Dis 1979 ;32:51-63.

7 Schor S, Karten I. Statistical evaluation of medical journal manuscripts. fAMA 1966;195:1123-8.

8 Anonymous. A pillar of medicine. $\mathcal{F} A M A$ 1966;195:1145

9 Gore SM, Jones IG, Rytter EC. Misuse of statistical methods: critical assessment of articles in BMF from January to March 1976. $\mathrm{Br} \mathrm{Med} \mathcal{F}$ $1977 ; \mathrm{i}: 85-7$.

10 Feinstein AR. A survey of the statistical procedures in general medical journals. Clin Pharmacol Ther 1974;15:97-107.

11 Ambroz A, Chalmers TC, Smith H, Schroeder B, Freiman JA, Shareck EP. Deficiencies of randomized control trials. Clin Res $1978 ; 26: 280$ A

12 Gifford RH, Feinstein AR. A critique of methodology in studies of anticoagulant therapy for acute myocardial infarction. $N$ Engl $\mathcal{F}$ Med $1969 ; 280: 351-7$.

${ }^{13}$ Peto R. Clinical trial methodology. Biomedicine (special issue) $1978 ; 28$ : 24-36.

14 Horwitz RI, Feinstein AR. Methodologic standards and contradictory results in case-control research. Am $\mathcal{f}$ Med $1979 ; 66: 556-64$.

${ }^{15}$ Muller M. Why scientists don't cheat. New Scientist 1977;74:522-3.

This is the first in a series of eight articles.

No reprints will be available from the author.

\title{
An audit of antenatal care: the value of the first antenatal visit
}

\author{
P K CHNG, MARION H HALL， I MACGILLIVRAY
}

\section{Summary and conclusions}

A critical analysis of the events recorded at the first antenatal visits in a city where all pregnant women are seen by specialist obstetricians for booking for antenatal care and confinement showed that many women attended too late for optimal care. The selection of women for their risk of complications was not very effective, partly because of failure to take account of information that was available, but mainly because many obstetric complications cannot be predicted, except by classifying large proportions of pregnant women as high risk. Even with the greatest care, inappropriate bookings are made at the first visit, and reappraisal of booking for continuing care and confinement is necessary during pregnancy.

\section{Introduction}

The first antenatal visit provides an opportunity to review the medical and obstetric history of the pregnant woman, make a physical examination, perform appropriate investigations, arrange suitable antenatal care for the rest of the pregnancy, and

\footnotetext{
Department of Obstetrics and Gynaecology, University of Aberdeen, Aberdeen AB9 2ZD

P K CHNG, MB, MRCOG, registrar

MARION H HALL, MD, MRCOG, consultant

I MACGILLIVRAY, MD, FRCOG, regius professor
}

book the confinement in a setting with the facilities and professional expertise likely to be necessary. Advice on diet, drug consumption, and other health matters may be given, and problems discussed.

It might be thought that if the first antenatal visit screening were performed by specialist obstetricians in a teaching hospital with an accepted unit policy then subsequent obstetric difficulties in those selected as abnormal could be reduced to a minimum, and women selected as normal could anticipate a problem-free pregnancy and confinement. We report our attempts to discover whether this was so in a city where general practitioners refer all pregnant women to specialist obstetricians.

\section{Methods of study and population}

This study was a retrospective analysis of the case records from the city district of Aberdeen of all 2186 women who delivered in 1975. Details of maternal characteristics, past obstetric and medical history, abnormal findings and investigations at all antenatal visits (both to hospital and general practitioner), and complications of the entire pregnancy were obtained by an experienced obstetric registrar (PKC) and punched on to computer tape for analysis.

Initially 2186 women (including 23 sets of twins) were included in the study. We excluded 11 because they had no antenatal care at all and 268 because their general practitioner records were not available. Thus the complete analysis was made for 1907 women.

The options open to the obstetricians arranging antenatal care were (a) hospital care, where women would be seen usually by an obstetrician of registrar grade or above but occasionally by senior house officers in training or $(b)$ combined care, where women would attend hospital only at booking, at 34 , and at 40 weeks' gestation, and attend her general practitioner for all other visits. The options for booking for 
confinement were (a) Aberdeen Maternity Hospital (AMH) with full obstetric and paediatric specialist facilities and $(b)$ Aberdeen Maternity Homes, two small nursing homes two miles from AMH fully staffed by midwives, with obstetric and paediatric residents and registrars on call but without facilities for fetal monitoring, operative delivery, or intensive care of the newborn.

An analysis of the return visits is presented elsewhere. ${ }^{1}$ Here we describe the achievements of the first visit.

\section{Results}

\section{GESTATION AT BOOKING}

Women were usually referred promptly to the central hospital clinic after attending their general practitioner. Table I shows that only $33 \%$ had attended the hospital clinic by 12 weeks' gestation and only $75 \%$ by 18 weeks' gestation.

Analysis by parity showed that primigravidae tended to appear earlier. There was little difference in gestation at first attendance with social class $\left(79^{\circ}\right.$ of social classes I-III had attended by 18 weeks compared with $73^{\circ} \%$ of IV and V), but marital status had a pronounced effect, with single women and those who married during the pregnancy appearing for booking much later (table II).

TABLE I-Cumulative percentage of women booked by gestation

\begin{tabular}{ccr}
\hline $\begin{array}{c}\text { Gestation } \\
\text { in weeks }\end{array}$ & \multicolumn{2}{c}{ Women booked } \\
No & 0 \\
\hline 10 & 246 & 13 \\
12 & 620 & 33 \\
14 & 960 & 50 \\
16 & 1254 & 66 \\
18 & 1427 & 75 \\
20 & 1545 & 81 \\
30 & 1815 & 95 \\
40 & 1907 & 100 \\
\hline
\end{tabular}

TABLE II-Cumulative percentage of women booked by gestation and marital status

\begin{tabular}{cccc}
\hline & \multicolumn{3}{c}{${ }^{\circ}$ Booked by marital status } \\
\cline { 2 - 4 } $\begin{array}{c}\text { Gestation } \\
\text { in weeks }\end{array}$ & $\begin{array}{c}\text { Single } \\
(\text { No = 198) }\end{array}$ & $\begin{array}{c}\text { Prenuptial conception } \\
(\text { No }=185)\end{array}$ & $\begin{array}{c}\text { Married } \\
(\text { No = 1524) }\end{array}$ \\
\hline 12 & 16 & 18 & 36 \\
16 & 36 & 39 & 73 \\
20 & 52 & 65 & 87 \\
30 & 84 & 96 & 97 \\
40 & 100 & 100 & 100 \\
\hline
\end{tabular}

TABLE III-Recognition of significant previous medical history

\begin{tabular}{lrrrrr}
\hline & & \multicolumn{3}{c}{$\begin{array}{c}\text { Booked } \\
\text { for AMH }\end{array}$} \\
& No & \multicolumn{1}{c}{$\%_{0}$} & \multicolumn{1}{c}{ No } & \% \\
\hline $\begin{array}{l}\text { Previous medical history noted by } \\
\text { medical staff }\end{array}$ & 111 & 77 & 98 & 88 \\
Not noted & 33 & 23 & 19 & 58 \\
\hline Total & 144 & 100 & 117 & 81
\end{tabular}

\section{CLINICIANS SEEN}

It is the hospital policy that all women should be seen for booking by a consultant or senior registrar. This actually happened in $83^{\circ} \%$ of cases, the remainder being seen usually by registrars.

\section{RECOGNITION BY CLINICIANS OF PREVIOUS MEDICAL HISTORY}

Serious medical conditions, such as diabetes, epilepsy, and chronic renal disease, were identified in 144 women by the senior midwifery staff who take the initial history. The clinician was considered to have "noted" a serious condition if it was mentioned in the "special features" area of the case sheet. Table III shows that $23 \%$ of serious medical conditions were not noted by medical staff, and that where this happened the women were much less likely to be booked for confinement in AMH.

\section{RECOGNITION BY CLINICIANS OF PREVIOUS OBSTETRIC HISTORY}

Eighty-five women had had a caesarean section and in every case the history was noted by the clinician and appropriate booking for confinement in AMH made. Of 34 women with a previous perinatal death, all but one were noted by the clinician; she was booked for confinement in the maternity home, but the remaining 33 were appropriately booked for AMH.

A history of previous intrauterine growth retardation, defined as having an infant weighing less than the 10th percentile according to the tables of Thomson $e t \mathrm{al}^{2}$ was found to give a $27 \%$ risk of recurrence. Ascertainment by clinicians of such a previous history was, however, incomplete. There were 115 parous women in whom a previous baby had had growth retardation, but in only $37(32 \%)$ was the history noted by medical staff. Almost half the women were booked for combined antenatal care, and $32 \%$ were booked for confinement in the maternity homes. Combined care and confinement in the maternity homes were much more likely to be arranged when the previous history had not been noted.

Retained placenta is usually considered as likely to recur. A previous history was noted by medical staff in only $19(68 \%)$ of 28 cases, however, and less than half were booked for $\mathrm{AMH}$ even when it was noted. The condition, however, did not in fact recur in any of the 28 women with a previous history. This is perhaps not unexpected as the overall incidence is only $1.4 \%$.

Previous postpartum haemorrhage was noted by clinicians in only $26(15 \%)$ of 174 cases with a history, nevertheless $106(61 \%)$ were booked for AMH. The risk of recurrence is not in any event great $\left(6.3 \%\right.$ incidence in those with a previous history compared with $4.4^{\circ}$ o overall, and $4.0 \%$ in those without a previous history).

\section{PHYSICAL EXAMINATION}

Women of height under $152 \mathrm{~cm}$ were always booked for confinement in $\mathrm{AMH}$, and this policy may be justified as they were more than twice as likely as the general population to be delivered by forceps rotation or caesarean section (table IV).

Short women had only a slightly higher incidence of intrauterine growth retardation $(14 \%$ compared with $10 \%$ in the unselected population). Those women whose weight for height (at 20 weeks) was less than the 10th percentile in this population had a $20 \%$ incidence of babies with intrauterine growth retardation.

TABLE IV-Height and percentage distribution of mode of delivery

\begin{tabular}{lcc}
\hline Mode of delivery & Total population & Women $<152 \mathrm{~cm}$ \\
\hline Spontaneous & 73 & 53 \\
Low forceps & 12 & 17 \\
Forceps rotation & 5 & 11 \\
Breech & 2 & 2 \\
Caesarean section & 8 & 17 \\
\hline Total & 100 & 100 \\
\hline
\end{tabular}

\section{INVESTIGATIONS}

Blooc group, venereal disease research laboratory tests, haemoglobin, rubella haemagglutination inhibition, and bacteriuria were routinely tested for. The value of blood group and rubella haemagglutination inhibition testing is already well documented. There were no positive results on venereal disease research laboratory testing and in an extended study of six years in this area only one true positive result was found in over $\mathbf{4 0} 000$ pregnant women tested.

Of the $99.5 \%$ of the population tested, $3.7 \%$ had a haemoglobin of less than $10 \mathrm{~g} / \mathrm{dl}$ at booking, with a higher incidence in single women, those in social class $\mathrm{V}$, and women of parity 3 and over. The women with a low haemoglobin at booking were four times as likely as the unselected population to develop iron deficiency anaemia later, despite the prescription of oral iron for them. 
Of the 1787 asymptomatic women tested for bacteriuria, $12 \%$ were positive. These women were not treated with antibiotics. Urinary tract infection later in pregnancy was coded only if the clinical findings were supported by a positive urine culture. The overall incidence was $4 \%$. Those women with a previous history of urinary infection in addition to bacteriuria had a $28 \%$ incidence of later urinary infection, but those with bacteriuria alone had an incidence of only $6 \cdot 8 \%$. This will be discussed in detail elsewhere.

\section{PREDICTION OF PERINATAL DEATH}

There were 34 women with perinatal deaths in the study. Risk factors identified as being present at least twice as often in the perinatal death group as in the general population were $(a)$ parity $4+$ and $(b)$ social class not determined, usually because of single status. Using these factors in conjunction with previous perinatal death and significant medical history, it was found that half of the women with a perinatal death had no risk factors at all.

\section{PREDICTION OF NORMAL PREGNANCY AND CONFINEMENT}

Of the original total population of 2186 women, $1030(47 \%)$ were booked for confinement in the maternity homes. Only 534 ultimately delivered there, however, for reasons shown in table V.

TABLE V-Outcome in women booked for homes

\begin{tabular}{|c|c|c|c|c|c|}
\hline & & & & No & $\%$ \\
\hline \multicolumn{4}{|c|}{ Booking changed antenatally because of complications } & 304 & 30 \\
\hline Booking changed for research . . & .. & $\cdots$ & .. & 73 & \\
\hline Maternity homes full . . $\quad$. & .. & . & . & 24 & \\
\hline Transfer during labour $\quad \ldots$ & .. & . & .. & 95 & $\begin{array}{r}9 \\
52\end{array}$ \\
\hline Delivered in maternity homes & .. & . & .. & & 52 \\
\hline 'Total & & & & 1030 & 100 \\
\hline
\end{tabular}

A further analysis on the outcome of the women whose booking was changed during pregnancy from the maternity homes to AMH was carried out by Chng and Hall. ${ }^{3}$ The perinatal mortality rate (16 per 1000 ) for this group of women was only slightly less than in those originally booked for AMH (19 per 1000) but considerably higher than that of the women confined in the maternity homes (7 per 1000), suggesting that the change of booking was justified.

Although only $9 \%$ of the original total were transferred in labour, this group constitutes $14 \%$ of those still booked for the maternity homes at the end of pregnancy. Of those transferred, only $5 \%$ were predictable; $12 \%$ of transfers were considered unnecessary. Although most were primigravidae, $26 \%$ were multigravidae.

\section{Discussion}

The late attendance of many women for their first antenatal visit reduces the potential benefits of serum $\alpha$-fetoprotein screening, amniocentesis for chromosomal and other fetal abnormalities, selection for procedures such as Shirodkar suture, clarification of uncertain dates, and advice on diet and drug consumption, especially since the women who attend late are those with a higher risk of perinatal problems and death. Health education on the need to attend early requires more emphasis.

Recognition by obstetricians of important items in the previous medical and obstetric history already elicited by midwives was not complete, and apparently inappropriate arrangements for antenatal care and confinement were sometimes made. It was not possible to show that the experience of the obstetrician made any difference in determining appropriate booking since the numbers of women with each risk factor seen by each specialist were small. An examination of the experience of individual consultants was not feasible.

The value of physical characteristics, such as short stature in the prediction of operative delivery and of low weight:height ratio in the prediction of intrauterine growth retardation (D M
Campbell, unpublished findings), was confirmed. Some routinely performed investigations, such as venereal disease research laboratory and bacteriuria testing, require further evaluation.

Half of the perinatal deaths that occurred had no readily identifiable risk factor at booking. Selection at first visit of women suitable for confinement without specialist attention was not very successful, as only just over half of those so selected were delivered without specialist attention, the remainder having the booking changed antenatally because of antenatal complications, such as pre-eclampsia and antepartum haemorrhage, or requiring transfer in labour. The proportions requiring change of booking or transfer in labour are similar to those described in various studies of general practitioner units. ${ }^{4-6}$

It appears therefore that even if the booking antenatal visit is performed by specialist obstetricians with an agreed policy of both assessment and booking many problems will later arise that were either not predictable or not predicted. Some improvement could be achieved by paying more attention to previous medical and obstetric history, but women will always need further surveillance later in pregnancy, and suitable arrangements for confinement must always be made to deal with unpredictable complications.

We are indebted to Mrs Kathleen McIntosh, Mrs Muriel Mair, Mrs Aileen Stone, and particularly to Mr M Samphier, for help with data processing. We thank our obstetric and general practitioner colleagues for permission to study their case records. The study was funded by the Health Services Research Committee of the Scottish Home and Health Department, and Dr Pang K Chng was employed as a res:arch registrar.

\section{References}

${ }^{1}$ Hall MH, Chng PK, MacGillivray I. Is routine antenatal care worthwhile? Lancet 1980 ;ii:78-80.

2 Thomson AM, Billewicz WZ, Hytten FE. The assessment of fetal growth. Fournal of Obstetrics and Gynaecology of the British Commonwealth 1968; 75:903-16.

${ }^{3}$ Chng PK, Hall MH. Appraisal of outpatient antenatal care in a teaching hospital. In: Chalmers I, Enkin MW, eds. Effectiveness and satisfaction in antenatal care. Clinics in developmental medicine. London: Heineman (in press.)

4 Marsh GN. Obstetric audit in general practice. Br Med f 1977;ii:1004-6.

5 Lewis BV, Tipton RH, Sloper IMS. Changing pattern in a general practitioner obstetric unit. $\mathrm{Br} M e d \mathcal{F} 1978$;i:484-5.

${ }^{6}$ Shapland DE. Extended role for general practitioners in obstetrics ? A medical audit. $\mathrm{Br} \mathrm{Med} \mathcal{F} 1979 ; \mathrm{i}: 1199-1200$.

(Accepted 27 August 1980)

Could endogenous peptides be responsible for some narcolepsy-like conditions? Would there be any danger of a trial of naloxone as a raiser of sleep threshold?

There is good evidence, at least from animal studies, that brain peptides are concerned in the control of sleep, ${ }^{12}$ but these seem unrelated to the brain and opiate peptides. The best characterised is one that induces sleep associated with delta waves on the EEG in rabbits and consists of nine amino-acid residues. There seems little doubt that similar sleep-controlling substances exist in the human brain, and disturbances in these neuropeptides may well occur in narcolepsy. There is no evidence to date, however, that the endogenous opiate peptides of the brain are concerned in sleep control or narcolepsy. As an opiate antagonist, therefore, naloxone would be unlikely to be effective in raising the sleep threshold, but there would be no harm in trying. This compound appears free of side effects, and indeed in many centres doses of 50 or more times the conventional antinarcotic dose $(0.4 \mathrm{mg})$ are being given in normal or patient volicteers during opiate research studies without harmful effects.

${ }^{1}$ Schoenenberg GA, Monnier M. Characterisation of delta-electro-encephalogram (sleep)-inducing peptide. Proc Natl Acad Sci 1977;74:1282-6.

Monnier M, Gaillard JM. Biochemical regulation of sleep. Experientia, 1980;36, 21-4. 